\title{
TEORÍA CRÍTICA Y DERECHOS HUMANOS: HACIA UN CONCEPTO CRÍTICO DE VÍCTIMA
}

\author{
Alán Arias Marín ${ }^{1}$ \\ Universidad Nacional Autónoma de México
}

http://dx.doi.org/10.5209/rev_NOMA.2012.v36.n4.42298

Resumen.- En el presente artículo, se desarrolla la construcción de un concepto crítico de víctima que logre solventar los requerimientos y desafíos contemporáneos en que se encuentran los derechos humanos y, particularmente, resistir, aminorar y/o normalizar la violencia presente en las sociedades contemporáneas.

El artículo despliega los argumentos acerca de la plausibilidad de un concepto crítico de víctima, como fundamento para un renovado discurso de los derechos humanos. Con ello, se pretende transitar de una víctima recluida y de significado restrictivo hacia una situación real y multidimensional de sujetos complejos afectados por esa violencia (no sólo víctimas de delitos), así como despojar la connotación sacrificial que el concepto de víctima mantiene, mediante la deconstrucción de los elementos de orden político, autorreferenciales y vinculados a la limitada idea derivada del espectáculo del cuerpo sufriente inmolado.

El texto, luego de partir de un rastreo etimológico de los diversos significados de víctima así como de la revisión del concepto jurídico de víctima, se concentra en enunciar algunos obstáculos epistemológicos en su conceptualización, a saber: (a) el carácter político en la determinación de la víctima; (b) la auto-designación de la víctima y su correlato de credibilidad; (c) el cuerpo sufriente de la víctima como el espacio del menosprecio.

Palabras clave.- víctima, derechos humanos, dignidad, juridicismo

Abstract.- This article analyzes the dominant concept of victim. This approach aims towards building a critical concept of the victim that solves the contemporary needs and challenges found in human rights, and, as a derivation, to resist, diminish and/or normalize violence present in societies contemporary.

The article deploys the arguments about the plausibility of a critical concept of victim, as the basis for a renewed human rights discourse. With this, intend to move from a notion of victim whit restricted meaning to a real and multidimensional situation of complex subjects victimized by different kinds of violence, also the concept of victim maintains though the deconstruction of the elements of a political order, self-referencing and linked to the limited idea of the spectacle of an immolated suffering body.

The text starts with an etymological tracing of the various meanings of the victim together with a revision of the legal definition of victim of it. It then focuses of the major epistemological obstacles present in the dominant concept of victim, namely: (a) the political character in the determination of the victim, (b) the self-designation of the victim and its credibility correlate, and (c) the ailing body of the victim as the space of contempt.

Keywords.- victim, human rights, dignity, legalism

\footnotetext{
${ }^{1}$ Profesor FCPS-UNAM; Investigador Centro Nacional de Derechos Humanos-CNDH. México.
} 


\section{1.- Preliminares}

La constelación teórica: víctima-violencia-dignidad vertebra el pensamiento clásico de los derechos humanos. La relación entre violencia y dignidad vulnerada no es directa, ésta se encuentra mediada por la noción de víctima. La noción de víctima, en su doble dimensión, como sujeto afectado por violencia violatoria de su dignidad humana (también, en el ámbito del derecho, como sujeto pasivo de la realización de algún delito $\mathrm{y}$, por tanto, de una violación del derecho), posee las características epistemológicas necesarias para establecer las mediaciones requeridas relativas al concepto de dignidad humana.

Por ello, el estudio de las víctimas y, desde esa perspectiva, la pretensión crítica resulta un asunto crucial, dotado de relevancia estratégica para el discurso social, filosófico y jurídico de los derechos humanos y su necesaria relegitimación. En este sentido, la construcción de un concepto crítico de víctima, capaz de satisfacer suficientemente los requerimientos y desafíos de la condición contemporánea de los derechos humanos resulta pertinente. Por ello, se ensayan aquí tan sólo los pasos iniciales de una aproximación crítica al concepto de víctima.

De igual manera, la multiplicación de las víctimas de la violencia -un sufrimiento socialmente producido ya inasimilable- potenciadas por el conflicto armado interno (de nuevo tipo ${ }^{2}$ ) y el incremento ostensible de violaciones a los derechos humanos durante -al menos- la última década, incrementa la importancia y agudiza la necesidad de una reflexión crítica sobre la víctima en el seno de un discurso renovado de los derechos humanos. Discurso que tiene la exigencia de ubicar a la noción de víctima y a las víctimas de las diferenciadas violencias en el corazón de la teoría y la práctica de los derechos humanos, esto es, una vinculación orgánica del concepto de víctima con el proyecto del movimiento histórico de los derechos humanos, su práctica discursiva y su politicidad intrínseca.

Se han desarrollado un buen número de reacciones e iniciativas de la sociedad civil y de la sociedad política para resistir, aminorar y/o normalizar ese plus de violencia $^{3}$. Ese conjunto práctico constituye una masa crítica relevante que sirve como referente constante -algunas veces explícito y siempre implícito- a las reflexiones que siguen. Conviene enfatizar que el núcleo racional que

\footnotetext{
${ }^{2}$ Ver Mary Kaldor, New and Old Wars: Organized Violence in a Global Era. Cambridge, Polity Press, 1999 y Peter Lock, "Transformações da guerra: a dominação da violência reguladora", en Theotonio Dos Santos (coord.) Hegemonia e Contra Hegemonia, Globalização Dimensões e Alternativas, vol. II, Río de Janeiro, Ed.PUC-Rio/Loyola, 2004.

${ }^{3}$ Amparo en materia de derechos humanos (junio 2011); asunción práctica -explicitada jurisprudencialmente por la Suprema Corte de Justicia de la Nación (SCJN)- de la jurisdicción de la Corte Interamericana de Derechos Humanos (CoIDH) (julio, 2011); mandato judicial de la misma CoIDH al gobierno mexicano para reformar el Código Militar en lo referente al juicio civil de la comisión de delitos y violaciones a los derechos humanos perpetrados por la fuerza armada (Ejército y Marina Armada) en contra de civiles (noviembre, 2009); la crucial reforma constitucional en materia de derechos humanos (junio 2011) y -muy recientemente- la Ley General de Víctimas (abril 2012).
} 
articula todos esos esfuerzos pueden inscribirse conceptualmente en la constelación teórica: víctimas-violencia-dignidad. ${ }^{4}$

Ya se han ensayado ejercicios teóricos de intencionalidad crítica, en los que se ha tratado de mostrar la pertinencia y plausibilidad de un uso metodológico (en sentido fuerte, no de mera técnica investigativa) de la noción de víctima. Se ha pretendido mostrar su funcionalidad epistemológica y heurística'; ¿pero, posibilita el concepto de víctima, en sus contenidos y acepciones éticofilosóficos (articulado a las funciones gnoseológicas ya indicadas), un empeño de fundamentación del discurso de los derechos humanos?

El periplo que aquí se ensaya es solamente una inicial aproximación a la cuestión planteada. Se establecen elementos del nuevo significado, visibilidad y relevancia que la víctima ha adquirido en el discurso de los derechos humanos en las últimas décadas; un breve rastreo etimológico que permite dejar asentados contenidos de carácter sacrificial que perduran pese al desarrollo secularizante de los significados de víctima; asimismo, se especifican las determinaciones centrales que se predican del concepto jurídico de víctima en los principales instrumentos internacionales. Se establece la actitud epistemológica y el talante crítico que guía el empeño de situar y enunciar los principales obstáculos epistemológicos (que ocultan significados sacrificiales), como condiciones de posibilidad iniciales para un proyecto de construcción de un concepto crítico de víctima.

Un recurso de método obligado, que conforma el objetivo central del texto, radica en la crítica al concepto dominante de víctima. Como veremos, sus dos determinaciones hegemónicas, juridicismo y sacrificialidad, imponen limitaciones restrictivas en las connotaciones de la noción dominante de

4 Jürgen Habermas, "El concepto de dignidad humana y la utopía realista de los derechos humanos", en Revista de Filosofía Diánoia, Vol. 55, Núm.64, México, mayo, 2010, p. 5. Las consideraciones que aquí se presentan están ubicadas en el horizonte de una contribución a un discurso crítico de los Derechos Humanos. Se entiende la condición actual de los derechos humanos como un campo teórico y práctico atravesado por una tensión bipolar, como un discurso dominante en la globalización -valorativa y normativamente- y, a la vez, un discurso pervertido y vulgarizado, cuya práctica es refuncionalizada por intereses políticos geoestratégicos globales y de equívoca legitimación política de muchos Estados nacionales y, también, en otro plano, de las instituciones y organizaciones públicas y privadas para su defensa y promoción. El espacio de la intervención teórica es la discusión contemporánea de los derechos humanos, marcado por el debilitamiento de su tradicional dominio jurídico y la irrupción plural del conjunto de las ciencias y disciplinas sociales y de la filosofía; nueva situación condicionada por el quebranto de la concepción rígida de soberanía nacional y el repliegue del Estado nacional de algunas de sus esferas habituales de influencia. La discusión crítica del discurso de los derechos humanos está determinada por un triple imperativo que lo determina e interpela: el imperativo epistemológico de una aproximación y construcción multidisciplinaria del objeto y sus prácticas, el imperativo multicultural que cuestiona su sentido de universal validez valorativa y jurídica, así como por el imperativo de género, con sus cuestionamientos al paradigma liberal y sus ejes fundamentales, el racionalismo y el humanismo y la problematización "feminista" a la desigualdad y la discriminación de la mujer. Se trata de interpelaciones imposibles de ser desatendidas por los derechos humanos. Ver Alan Arias, "Tesis sobre una aproximación multidisciplinar a los Derechos Humanos", Revista Derechos Humanos México, No. 12, CNDH, México, 2009; también: "Globalización, cosmopolitismo y derechos humanos. Apuntes sobre el contexto teórico y la reforma constitucional", Revista Derechos Humanos México, No. 18, México, 2011.

${ }^{5}$ Ver Alan Arias, "Derechos humanos: entre la violencia y la dignidad", Revista Derechos Humanos México, CNDH, No. 19, México, 2012. 
víctima. El desafío es -en consecuencia- transitar de la norma que hay que observar y su significado restrictivo, referida al delito tipificado, hacia la situación real y multidimensional de sujetos complejos afectados por esa violación a la ley, por un lado. Y, por otro lado, despojar la connotación sacrificial que el concepto de víctima mantiene, mediante la desconstrucción de los elementos de orden político, autorreferenciales y vinculados al espectáculo del cuerpo sufriente inmolado. Esa operación desconstructiva ensayada en un doble plano, tanto en el del derecho como en el de las connotaciones sacrificiales, conforma una dimensión decisiva en el tratamiento referencial necesario para la reconfiguración crítica del concepto de víctima ${ }^{6}$.

Finalmente, se sugiere la tesis acerca de la pertinencia y plausibilidad del concepto de víctima si este se construye de acuerdo a condiciones que superen sus significados de postración y queja que clama por un reconocimiento victimario menospreciado. Se esbozan, entonces, elementos para la producción de un concepto crítico de víctima -desconstruido- que trascienda el cuerpo sufriente de la víctima (y su espectáculo) por vía de un proyecto teórico y práctico (cuerpo-idea) de resistencia y emancipación.

Se trata de una aproximación inicial que, no obstante su carácter tentativo y provisional, conlleva pretensiones de objetividad teórica y que, por tanto, no puede condicionarse, como frecuentemente ocurre con el discurso y/o los movimientos victimales, por determinaciones emocionales, ideológicas 0 moralísticas. Se pretende una sobriedad discursiva apta para moverse en la clásica constelación conceptual del discurso de los derechos humanos: víctimas-violencia-dignidad. Se pretende rigor epistemológico y densidad ética, se recusa el sentimentalismo y la compasión.

No es éticamente aceptable renunciar y/o descartar a la víctima como el centro de gravedad ético-moral del discurso de los derechos humanos; pero no es políticamente viable asumirla en su mera prostración sufriente, como cuerpo victimado. Se trataría de un primer paso para construir una noción de víctima a partir -sí- del cuerpo humano sufriente de la dignidad violentamente vulnerada, pero también de un cuerpo-idea levantado de su postración, enhiesto, que propone y proyecta un pensamiento posible y una práctica de resistencia y emancipación afirmada en el reconocimiento de la igualdad de todos. Queda así sugerido el horizonte de que ese proyecto resistente y emancipador pudiera articularse con los derechos humanos, su discurso y el conjunto de prácticas que lo constituyen; tal articulación implicaría un reforzamiento a las potencialidades emancipatorias y críticas de los derechos humanos.

\section{2.- Relevancia contemporánea de la noción de víctima. Nueva visibilidad y memoria}

La significación de la memoria, en tanto forma específica de apropiación del pasado, se ha convertido en un aspecto decisivo, una especie de catalizador, para la eclosión de la noción de víctima contemporánea. El siglo XX, en esta perspectiva, será recordado por un suceso que no sólo sacudió a la humanidad

\footnotetext{
${ }^{6}$ La otra dimensión crítica del tratamiento de la noción de víctima es el de su uso metodológico (epistemológico y heurístico), mencionado más arriba. Ver supra Notas 3 y 4 e infra Nota 13.
} 
sino que cambió su porvenir: la Segunda Guerra Mundial. La memoria del pasado, la acción de recordar, tiene exigencias irrenunciables, particularmente manifiestas y determinantes en sentido político. Bajo ese condicionamiento, se puede afirmar la existencia, al menos, de dos formas de olvido radicalmente opuestas; una forma es la ignorancia, la otra, la injusticia. La ignorancia alude un olvido como desconocimiento del pasado, en cambio, la injusticia sugiere un olvido en el sentido de no dar importancia, ni significado alguno al pasado. Históricamente, quizás, el olvido de las víctimas tenga su origen en la injusticia o en el hecho irrebatible de que la justicia es prácticamente siempre la instaurada por los vencedores. ${ }^{7}$

Ese olvido muta sociológicamente en invisibilidad de las víctimas. De cierta forma, esa no visibilidad social resulta condicionada por determinaciones políticas. La figura de la "amnistía" sirve como ilustración y ejemplo; en su origen, significaba no tanto olvidar o perdonar, sino castigar a quien recordara infortunios pasados. Se trata - de alguna manera- de forzar políticamente un pasado ausente (silenciado) en el presente. La política es de los vivos, los muertos ya no están. El pasado vencido, el que contiene desdicha y dolor, desaparece de la historia, y, con ellos, sus testigos, esto es, sus víctimas. En un sentido complementario, la historia en Occidente y la especificidad de la modernidad radicarían en "el convencimiento de que el progreso produce víctimas y que para progresar hay que dar la espalda al pasado".

El contrapunto, hasta hace relativamente poco inédito en la historia, lo constituye una nueva visibilidad de las víctimas. Esta visibilidad no refiere principalmente a una visibilidad sociológica o histórica en sentido positivista. Consiste en haber logrado que el sufrimiento de las víctimas deje de ser insignificante, se trata de una rearticulación necesaria que subvierte el confinamiento invisibilizante de las víctimas evitando su aislamiento simbólico, la privatización incomunicable de su dolor y la invisibilidad política; se trata de una visibilidad de sentido y de interpretación de su existencia (su rescate como motivo hermenéutico). Esta novedad es, pues, un fenómeno epocal, un signo propio de nuestro tiempo. ${ }^{9}$

La serie de significaciones complementarias de este cambio, las rupturas de un tiempo civilizatorio respecto de otro ${ }^{10}$, resultan contemporáneamente en una concepción vinculada a la idea de la reconstrucción de la justicia, esto es, la posibilidad (en rigor una utopía plausible) de que la justicia, en algún momento quebrantada -la injusticia remite siempre a la destrucción de una relación-, encuentre condiciones para ser reconstruida. En ese sentido, surgen implicaciones específicas para pensar éticamente la injusticia (testimoniada por la víctima) si se logra establecer la posibilidad de un nuevo estatuto ético de la víctima. De esa nueva condición, construida a partir de las nuevas circunstancias históricas y culturales de las víctimas, se incentiva un impulso

\footnotetext{
${ }^{7}$ Danilo Zolo, La justicia de los vencedores. De Núremberg a Bagdad, Madrid, Trotta, 2006, pp. 157-183.

${ }^{8}$ Manuel-Reyes Mate, Justicia de las víctimas. Terrorismo, memoria, reconciliación, Barcelona, Anthropos Editorial, 2008, p. 20.

${ }^{9} \mathrm{Ibid}$, p. 21.

${ }^{10}$ Paul Ricoeur, Memory, History, Forgetting, Chicago, The University of Chicago Press, 2004, pp. 305 y sigs.
} 
moral nacido desde la perspectiva de una reflexión ética que apuntale y contribuya a la fundamentación del proyecto y el discurso de los derechos humanos.

Una reconstrucción ética, como elemento indisociable de esa cultura reconstructiva de la justicia ${ }^{11}$, exige el punto de vista subjetivo de los actores y la develación de su sufrimiento. La víctima racionaliza su experiencia y la comparte; denuncia y hace público el daño que ha sufrido. Desde el derecho, sobre todo el penal, se constata cada vez con mayor anuencia, la sustitución del vínculo entre justicia y castigo por el de justicia y reparación de las víctimas. Específicamente, en el plano de la argumentación hacia una justicia reconstructiva, de lo que se trata es de fijar de otra manera, más abierta, las prioridades de la reparación de las víctimas.

Vuelta al comienzo del argumento; el giro de esa visibilidad de las victimas lo constituye ese renovado elemento de la memoria, entendido como la posibilidad de interpretar aspectos significativos que hasta ahora no tenían ningún valor hermenéutico. La remembranza de lo que hasta ahora se encontraba olvidado, prohibido, no es más que el empeño de dar significación singular a lo que no parece tener sentido. El victimario modélico de la época contemporánea no sólo quiere dañar impunemente, sino, además, privar de sentido -y de sentido moral- lo que hace; a la muerte física de la víctima se añade su muerte metafísica, simbólica (la negación de su hermenéutica).

Ahora bien, si la modernidad se definía por su condición "post-tradicional", es decir, negándole al pasado cualquier poder normativo sobre el presente, es debido a que colocaba al individuo bajo un inusitado principio de autonomía, el sueño racional (que produce monstruos, como plasmó Goya) de que el individuo no tenía cadenas que lo ataban a lo que había sido. Las grandes conflagraciones mundiales del siglo $X X$ develaron cruelmente que el hombre no era tal sujeto autónomo y libre, que la humanidad se había colocado al servicio de la técnica y de las innovaciones tecnológicas, que el hombre era un peón al servicio de un destino sin rumbo que ahora estaba troquelado por la técnica.

Esa sensación de vértigo precipitó una mirada al pasado, fue el momento detonado enfáticamente por la literatura- de la irrupción iluminadora de la memoria. Para conseguir un equilibrio, un vaso comunicante, entre un pasado traumático y un porvenir incierto. Para entender esa metamorfosis, grandes escritores, principalmente centro-europeos empeñaron su talento. ${ }^{12}$ Como le narra Kafka a su padre, al referirse a su generación, "las dos patas traseras apoyadas en el pasado para que los cambios tuvieran una dirección y no fuera un dar vueltas sin sentido."13

Sin embargo, la Segunda Guerra Mundial sacudió a Occidente a modo de reiteración, pero con mayor radicalidad. Al final de la hecatombe, la autonomía

\footnotetext{
${ }^{11}$ Jean Marc Ferry, La ética reconstructiva, Bogotá, Siglo del Hombre Editores, 2001, pp. 16-17.

${ }^{12}$ Como grandes referencias la obra de Hermann Broch (Die Schuldlosen, Zúrich 1954, ed. por J. Weigand); Robert Musil (Der Mann ohne Eigenschaften, 1942 Rowohlt), Franz Kafka (Brief an den Vater, 1919), Elias Canetti (Die Blendung, 1936); Marcel Proust (À la recherche du temps perdu), André Gide (Si le grainnemeurt, 1924) .

${ }^{13}$ Franz Kafka, Letter to His Father. New York, Schocken Books, 1966. Ver también, Raquel Serur, "Lo trágico judío en Bellow y Kafka" en Revista Palos de la Crítica, No. 1, México, 1980.
} 
del individuo no pudo ser vista más que con recelo; de ahí el recurso a formulaciones personalistas en desdoro del individualismo posesivo, por ejemplo, en la Declaración Universal de los Derechos Humanos de 1948. El individualismo había conducido a abandonar la razón por la barbarie, tránsito facilitado por los nuevos despliegues de la tecnología en diversos y múltiples ámbitos; sólo entonces se colocó a la autonomía, bajo riesgo de perder nuevamente sentido, como forma autorreferencial de la idea de memoria.

El holocausto -Auschwitz como paradigma y concepto- resulta ejemplar, toda vez que constituye un proyecto no sólo de aniquilación sino de olvido; su intención de eliminar cualquier rastro para que fuera imposible la memoria. ${ }^{14}$ Todo debía ser destruido. Pese a ello, el proyecto fracasó y los sobrevivientes son el cuerpo sufriente de la barbarie y su testimonio el lugar donde yace el sentido de la remembranza; el compromiso del testigo se auto-proyecta como un deber de la memoria.

Así se ha conformado una centralidad de las víctimas -segunda mitad del siglo $X X$ y lo que va del XXI- que carga de implicaciones a la ética contemporánea y consecuentemente al discurso de los derechos humanos. Se ha impuesto el riesgo, moralmente grave, de vivir el presente y aspirar a construir el futuro sin atender al significado de las víctimas y sus consecuencias políticas. Sin embargo, este imperativo ético no puede ser formulado con simpleza positiva, al contrario, aparece como paradoja (lo diverso de la doxa, la opinión común y corriente) y reclama trabajo deconstructivo, labor de interpretación.

Las consideraciones anteriores refuerzan la pertinencia de construir -producirun concepto crítico de víctima que trascienda el cuerpo sufriente -y su espectáculo- por vía de un proyecto de resistencia y emancipación, que incorpora pero que no se agota en la queja y en la reparación. Proyecto práctico y discursivo capacitado para instaurar y/o emplazar acontecimientos de emancipación, situaciones prácticas de exigencia de reconocimiento, afirmación dederechos (libertades) e instauración de garantías de no repetición.

La revisión crítica de la noción de víctima, con la mira en la pretensión de contribuir a una fundamentación ética de los derechos humanos, supone asumirla como la mediación plausible entre las nuevas determinaciones y modalidades de la violencia estatal y societal contemporáneas y la dimensión de la dignidad humana. ${ }^{15}$ Su estudio, resulta un asunto crucial para el discurso social, filosófico y jurídico de los derechos humanos. Análisis y reinterpretación de la ecuación discursiva señera de los derechos humanos, el clásico nudo fundamental -históricamente siempre repensado- de la relación violencia-víctima-dignidad. Como se sabe, la relación entre violencia y dignidad vulnerada no es directa, se encuentra mediada por la noción de víctima, de ahí su importancia teórica y metodológica. Así, la problemática generada por el

\footnotetext{
${ }^{14}$ Primo Levi, Si esto es un hombre, Muchnick Editores, Barcelona, 2001; Giorgio Agamben, Estado de excepción, Adriana Hidalgo Editora, Buenos Aires, 2007; Esther Cohen, Los narradores de Auschwitz, Editoral Fineo, México, 2006.Ver también, Manuel-Reyes Mate, op. cit. p. 27.

${ }^{15}$ Ver Alan Arias Marín, "Derechos Humanos: entre la violencia y la dignidad" en Revista de Derechos Humanos México, México, No.19, 2012.
} 
tratamiento crítico ${ }^{16}$ de esos temas constituye actualmente -como desde su origen- la columna vertebral de los derechos humanos.

La perspectiva crítica de la idea de víctima propicia la apertura a una doble dimensión epistemológica, tanto propiamente cognoscitiva como en su función heurística: a) la víctima es punto de partida metodológico, plausible para una investigación crítica del núcleo básico ético de una teoría de los derechos humanos, a partir del estudio de la violencia; b) la víctima es la mediación necesaria con la dignidad dañada o vulnerada que se implica en ella, toda vez que la aproximación o el asedio conceptual a la idea de dignidad humana sólo ocurre idóneamente por vía negativa, esto es, a través de las múltiples formas de daño y de vulneración de la dignidad de las personas.

Ahora bien, el análisis de la noción de víctima tiene como vía de acceso el sufrimiento. Tanto la violencia como la dignidad humana (vulnerada) son perceptibles a partir de la vida dañada en las víctimas, cuyo registro radica en las narrativas del sufrimiento. Así, la meditación acerca del sufrimiento resulta inexcusable, en virtud de que aparece como la vía discursiva-material que comunica con la noción de víctima.

\section{3.- Observaciones etimológicas sobre la noción de víctima}

\section{a) Sacrificialidad}

Las reflexiones contemporáneas sobre el concepto de víctima refieren, de manera obligada, a su evolución etimológica y filológica puesto que ayuda a comprender y precisar los contenidos contemporáneos de la palabra víctima; tal repaso propicia un tratamiento conceptual de mayor extensión y complejidad con la intención de alcanzar un horizonte comprensivo y explicativo en la polisemia misma de los significados del término víctima.

Desde la perspectiva etimológica, se puede precisar que la palabra víctima proviene del vocablo latino victima: ser vivo sacrificado a un Dios; palabra que a su vez- tiene origen en el indoeuropeo wik-tima, el consagrado o escogido; wik del prefijo weik que significa separar, poner aparte, escoger. ${ }^{17}$

El término víctima aparece por primera vez (1490) en el Vocabulario de Alonso de Palencia, y significa: "persona destinada a un sacrificio religioso", según el Diccionario Etimológico de Corominas. ${ }^{18} \mathrm{El}$ mismo origen etimológico de víctima coincide con la acepción del Breve diccionario etimológico de la lengua española. ${ }^{19}$ A su vez, el Diccionario de la Real Academia Española, señala por víctima: "1. Persona o animal sacrificado o destinado al sacrificio. 2. Persona que se expone $u$ ofrece a un grave riesgo en obsequio de otra. 3. Persona que padece daño por culpa ajena o por causa fortuita. 4. Persona que muere por culpa ajena o por accidente fortuito. 5. Persona que padece las consecuencias

\footnotetext{
${ }^{16}$ Véase este argumento con mayor detalle en Alan Arias Marín, op. cit.

17 Alonso Rodríguez Moreno, "Hermenéutica del concepto de actual de víctima" en Revista Derechos Humanos México, México, núm. 13, año 5, 2010. p. 39.

${ }^{18}$ Breve diccionario etimológico de la lengua castellana, Madrid, Gredos Editorial, 1994.

${ }^{19}$ Breve diccionario etimológico de la lengua española, México, Fondo de Cultura Económica/Colegio de México, 1988.
} 
dañosas de un delito."20 Importa rescatar, pese a lo apretadamente esquemático de las referencias, que todas y cada una de las entradas señaladas nunca desliga la noción de víctima, su significante, de la idea de sacrificio, un significado persistente y versátil.

En cada una de las acepciones de los diversos diccionarios, se puede señalar que la etimología de víctima no guarda cambios mayores con respecto a su noción originaria, de carácter religioso, que denota relación al componente "sacrificio", esto es, la persona o animal sacrificado o que se destina al sacrificio. $^{21}$

Ese origen etimológico de la palabra víctima, en tanto palabra culta, apenas se ha diferenciado del latín, donde ocurrió su consagración lingüística; entre las lenguas romances, la palabra latina victima ha pasado idéntica al español, mientras que para el portugués se ha trasladado como vítima, asimismo, vittima para el italiano, victime en francés y victim en inglés. Como se ha indicado, el contenido perseverante de la palabra victima es el de "sacrificio"; a partir de lo cual, algunos estudios filológicos señalan que la palabra victima habría encontrado su origen como vocablo actual en el vocablo latino vincere, que significa: atar, lo que representa al sujeto atado; otros estudios en cambio, vinculan el origen de la palabra victima con otro vocablo latino viger, ser vigoroso, en alusión a la víctima como aquel animal robusto y grande para sacrificar. $^{22}$

En ese sentido, quedaría meridianamente establecido que la noción etimológica de víctima se encuentra estrechamente vinculada a la idea de un animal o ser humano destinado al acto de sacrificio, el que sufre o padece daño o dolor, debido a los intereses o pasiones de otro. Hay pues en los significados persistentes de la noción de víctima la referencia múltiple y versátil, producto de su evolución secularizante, respecto de quien es sacrificable o residuo del sacrificio. Lo sacrificial es significado predominante en el entendimiento más extendido de la noción de víctima; conforma uno de los rasgos definitorios de la noción dominante de víctima.

El significado etimológico de víctima ha vivido, como muestra su evolución filológica, su propio proceso de secularización. Una comprensión crítica de la secularización (tema crucial en sí mismo) ${ }^{23}$ del significado de víctima resulta decisiva para el desmonte crítico del concepto dominante de víctima. La secularización es paradoja. La secularización no consiste en el mero relegamiento de significados teológicos. La secularización es el concepto (clave) mediante el cual la autocomprensión de la modernidad ha querido liberarse pero también cerciorarse de sus vinculaciones arcaicas, hegemónicamente religiosas. Los nuevos significados, aún los más enfáticamente innovadores y/o liberadores, mantienen una signatura teológica;

\footnotetext{
${ }^{20}$ Diccionario de la lengua española, Madrid, 22a edición, Real Academia Española, 2001.

21 En este sentido, la noción de víctima es coincidente en los siguientes diccionarios: Diccionario de la Real Academia, Diccionario Sopena, Petit Larousse, Oxford English Dictionary, Vocabulario della Lingua Italiana, The Random House Dictionary, Dicionário Brasileiro de Língua Portuguesa.

${ }_{22}$ Rodrigo Ramírez González, La victimología, Bogotá, Editorial Temis, 1983, p. 4.

${ }^{23}$ Giacomo Marramao, Poder y secularización, Ediciones Península, Barcelona, 1989.
} 
los contenidos más secularizados sirven como una especie de velo que oculta viejos significados de raigambre teológica.

De las disciplinas sociales, el derecho destaca, en virtud de su determinación técnico-administrativa, en su operatividad de encubrimiento de viejos contenidos religiosos bajo el velo formal de su operatividad moderna. Foucault ha referido sintomáticamente tal complicidad al referirse a la presencia y persistencia de los significados religiosos en las operaciones modernas del derecho penal, la purga de la pena y las penitenciarías como los espacios idóneos no tanto de reinserción social de los delincuentes sino del sentido del castigo derivado del penar de los pecados y la penitencia. ${ }^{24}$

Un ejemplo sintomático de este sentido paradojal de la secularización vinculado a la noción de víctima y su significado arcaico sacrificial dominante es la propuesta de Ignacio de Ellacuría. Una tematización de la víctima cargada de contenidos religiosos, no obstante, elaborada desde la teología de la liberación, probablemente uno de los esfuerzos secularizantes más vehementes de la teología contemporánea. La filosofía política liberadora (en algunos casos, revolucionaria, principalmente en América Latina, enfáticamente, en Brasil) que cohabita con la teología de la liberación, asume que el objeto y punto de partida (de la revelación) es la historia ${ }^{25}$ y ya no sólo los clásicos datos revelados de las Sagradas Escrituras y la doctrina de la Iglesia (católica) y su magisterio. La centralidad de este planteamiento deriva en la reflexión de la politicidad de la filosofía-teología con objeto de hacerla efectiva en el cambio socio-político; de tal forma que cumpla con una función liberadora. La perspectiva de la víctima es uno de los temas fundamentales para el pensamiento de la liberación.

¿Cómo llamar a las víctimas individuales y a las víctimas masivas de hoy? La teología de la liberación busca responder a la novedad semántica y epistémica de la idea de víctima, ante las novedosas formas de victimización en la actualidad. Los planteamientos de Ellacuría sobre las víctimas se identifican con la idea de un "pueblo históricamente crucificado" 26.

Llamar a esas mayorías "pueblo crucificado" significa no sólo otorgar "dignidad" a sus muertes, sino ver en ellos un potencial salvífico. Cancelar el silencio que se cierne sobre ellas en nuestro mundo. Las víctimas han quedado (a diferencia de los muertos americanos en Viet-Nam o los asesinados en Nueva York el 11 de septiembre) sin nombre porque no son "ricos", sino que son "pobres". La noción "pueblo crucificado" para designar a las víctimas, mantiene viva la pregunta de la teodicea, pues en la fe de la religiosidad se procura afecto, compasión, al "pueblo crucificado", pero en la historia no se puede hacer nada por él. Ellacuría señala que "esas mayorías, oprimidas en vida y masacradas en muerte son las que mejor expresan el ingente sufrimiento del mundo". ${ }^{27}$

\footnotetext{
${ }^{24}$ Michel Foucault, Defender la sociedad, Fondo de Cultura Económica, Argentina, 2001; también el clásico Vigilar y castigar, Siglo XXI, México, 1976, pp. 216-218.

${ }^{25}$ Teilhard du Chardin, El medio divino, Taurus, Madrid, 1965.

${ }^{26}$ Ignacio de Ellacuría, Mysterium liberationis. Conceptos fundamentales de la Teología de la Liberación, tomo II, Madrid, UCA/Trotta, 1990, pp. 189-216.

${ }^{27}$ Ibid. p. 204.
} 
¿Qué condiciones se requieren para que se produzca el desprendimiento de un significado -adherido a su época- respecto del significado dominante que le ha precedido? En el caso que aquí se estudia, ¿qué se necesita para un vaciamiento (kénesis) de lo sacrificial presente en el concepto contemporáneo de víctima? Antes que nada, la superación de los obstáculos epistemológicos pero también políticos- como preliminar para la construcción de un nuevo concepto crítico (desconstruido) de víctima; conviene al argumento del texto establecer los elementos generales de ese desprendimiento o vaciamiento de significados retrógrados inherente al proceso de secularización ${ }^{28}$ en lo que concierne al concepto de víctima.

Así, la crítica de los contenidos sacrificiales presentes, aún si velados por el formalismo jurídico y su obsesión por la tipificación del delito, en el concepto preponderante de víctima, implicaría la autoafirmación de la víctima a partir (o referidos desde) contenidos semióticos contrarios a la idea de sacrificio o ajenos a ella. Un nuevo concepto de víctima habrá de construirse superando (aún si conserva) los contenidos limitados al daño, el dolor, el cuerpo sufriente, el delito y/o el crimen; más en general, por vía de la autoafirmación de la víctima, la obtención de reconocimiento, pero desechando la construcción de una idea de justicia a partir del daño infligido o la dignidad vulnerada, sino de un reconocimiento (a partir sí del cuerpo sufriente y la dignidad vulnerada) de la autocapacidad de resistencia y emancipación fundada en la afirmación de la igualdad de todos.

\section{b) Juridicismo}

En todo caso, a lo largo del itinerario de la definición de víctima se destaca que el término ha sido utilizado también en acepciones más amplias, que buscan trascender su carácter religioso. Esta incorporación de significados ha sido tarea desarrollada primordialmente por diversas ramas del derecho. Las diversas acepciones de víctima, principalmente las acuñadas por los estudios de victimología, han incorporado nuevos elementos en su definición, tales como: (1) la afectación, tanto en el plano individual o colectivo, determinada por factores de origen físico, psíquico, económico, político o social, así como del ambiente natural o técnico ${ }^{29}$; (2) el sufrimiento resultado de un designio, incidental o accidental ${ }^{30}$; (3) el sufrimiento de manera injusta ${ }^{31}$. Con ello, se puede indicar que dos rasgos decisivos de la definición jurídica de víctima, que refuerzan sus contenido sacrificial, lo constituyen el sufrimiento y la injusticia ${ }^{32}$.

Adicionalmente, uno de los elementos trascendentes en la definición de víctima es el de crimen. Lo anterior conduce a referirse a la definición de víctima desde su carácter jurídico, la cual cabe recordar que constituye, junto con los contenidos sacrificiales ya referidos, la noción dominante.

\footnotetext{
${ }^{28}$ Ver Hans Blumenberg, La legitimación de la Edad Moderna, Pretextos, Valencia, 2008.

29 Benjamin Mendelson, Victimas y las tendencias de la sociedad contemporánea, INALUD, núm. 10, año 4, San José, 1981, p. 58.

30 Paul Separovic, Victimology, a new approach in social sciences, I Symposium, Tel Aviv, 1973.

${ }^{31}$ Vasile V. Stanciu, Etat Victimalet Civilisation. Etudes Internationales de Psychosociologie Criminelle, París, 1975, p. 29

${ }^{32}$ Ibid.
} 
De manera sucinta se puede señalar que, desde la perspectiva jurídica, víctima es la persona que sufre la acción criminal, esto es, la persona cuyos derechos han sido violentados en actos deliberados. ${ }^{33}$ Se trata, a todas luces, de una comprensión restrictiva de la noción de víctima (volveremos más adelante a la revisión y análisis de tal noción jurídica de víctima).

Respecto de lo anterior, la cuestión nodal para una noción más extensa de víctima constituye el planteamiento de una definición de víctima sin referencia a la acción criminal. Es decir, asumir la situación victimal sin la mediación de una conducta antisocial; con ello se dejaría de lado la noción restrictiva de víctima determinada por la figura del delito. De modo que se puede ser víctima, en un sentido más amplio, si se incluyen nuevas formas de victimización y se extienden las posibilidades de situaciones que propicien o devengan en una victimización. Esta definición ampliada de víctima, logra incorporar, en principio, a las personas que se convierten en víctimas sin intervención humana; víctimas por desastres naturales o ataques de agentes biológicos son ejemplo de este tipo de victimización. También se puede dar una victimización cuando las personas resulten ser víctimas por conducta propia (auto-victimización). Asimismo, se puede señalar que existe una victimización sin delito, esto es, la persona puede sufrir un daño causado por una acción que no se encuentre sancionada en ninguna ley penal, pero que constituye una inflicción de daño o sufrimiento resultado de una conducta antisocial. ${ }^{34}$

Dado el carácter original y persistente de la etimología de víctima, lo sacrificial de contenido religioso, hasta el contenido jurídico que alude a un acto ilícito; resulta necesario estructurar un concepto crítico de víctima con potencialidades comprensivas y explicativas para el fenómeno (sus finalidades, $y$, sus causas y efectos). El sufrimiento consciente en la víctima no basta para definir su propia condición -este problema se angosta a la autodefinición de víctima y deviene en una cuestión de creencia; existe también la posibilidad de concebir una víctima inconsciente; tampoco queda zanjada la cuestión mediante alguna determinación política que establezca el estatuto de quién es víctima y quién no lo es; ni la asunción del carácter de víctima bajo la determinación del espectáculo del cuerpo sufriente. Todo lo anterior implica necesariamente y abona en el sentido de un proceso de victimización más amplio y complejo que el que la noción dominante de víctima contiene. Concepto de víctima dominante definido y delimitado por la categoría de delito, cargado -a su vezde significaciones múltiples que contienen en sí mismas el periplo de la secularización del sacrificio y de la historia del derecho en las sociedades occidentales.

\footnotetext{
${ }^{33}$ Henry Pratt Fairchild, Diccionario de Sociología, México, FCE., 1980, p. 311.

34 En este sentido, sin embargo, Rodríguez Manzanera, señala que existen al menos cuatro posibilidades de victimización: a) sin delito ni conducta antisocial; b) sin conducta antisocial con delito; c) sin delito con conducta antisocial; d) con delito y con conducta antisocial. De lo anteriormente expuesto, se reafirma la necesidad de proteger a las posibles víctimas a partir de las diversas y variadas posibilidades que presenta el fenómeno victimógeno. Luis Rodríguez Manzanarera, Victimología, México, Editorial Porrúa, 1988, p. 71
} 


\section{4.- La víctima en el derecho internacional de los Derechos Humanos}

No fue hasta después de la Segunda Guerra Mundial, cuando las violaciones graves de los derechos humanos adquirieron relevancia en el ese entonces recientemente (re)inaugurado discurso de los derechos humanos y del derecho internacional humanitario. En este campo convulsivo, luego de la barbarie, surgieron los organismos internacionales y regionales de protección de los derechos humanos y, junto a ellos, la necesidad de consolidar un estatuto de carácter internacional de víctimas de violaciones graves de derechos humanos.

Sin embargo, no se habían logrado capitalizar, en términos de una reflexión orientada por los derechos humanos, las preocupaciones sustanciales vinculadas a las violaciones de los derechos humanos de las víctimas, pues su afirmación y eficacia práctica en la protección, prevención y reparación de las víctimas se encontraba, en buena medida, limitada por su tipificación escueta.

Hace menos diez años, se logró adoptar una norma común sobre los derechos de las víctimas de violaciones graves de derechos humanos. En ella se incorporaron una serie de elementos de importante significación, relativos a la reparación del daño y construidos con elementos teóricos y criterios vinculados a la llamada cultura legal reconstructiva. ${ }^{35}$

Se trata de la Resolución 60/147, aprobada, sin votación, por la Asamblea General de las Naciones Unidas el 16 de diciembre de 2005. En dicha resolución, se sancionan los Principios y directrices básicos sobre el derecho de las víctimas de violaciones manifiestas de las normas internacionales de derechos humanos $y$ de violaciones graves del derecho internacional humanitario a interponer recursos y obtener reparaciones. ${ }^{36}$

La Resolución 60/147 tiene como precedente los trabajos de la antigua Comisión de Derechos Humanos de Naciones Unidas en Ginebra, establecida en 1946, cuyos objetivos fueron el establecimiento de normas y mecanismos para vigilar y proteger la situación de los derechos humanos. Cabe recordar que en el seno de esa desaparecida Comisión de Derechos Humanos se llevaron a cabo, en 1948, los trabajos que concluyeron con la histórica Declaración Universal de Derechos Humanos. Asimismo, dicha Comisión fue la principal encargada de establecer la estructura jurídica internacional para protección de los derechos humanos, vigente hasta su desaparición en marzo de 2006.

La Resolución 60/147, en virtud del carácter unánime de su adopción, así como por la naturaleza general y fundamental de su contenido, es susceptible de ser interpretada como una opinio juris communitatis (opinión jurídica de la comunidad internacional) por lo que cabe la pregunta de si se podría considerar obligatoria para todos los Estados. ${ }^{37}$

\footnotetext{
${ }^{35}$ Cfr. Jean Marc Ferry, La ética reconstructiva, Bogotá, Siglo del Hombre Editores, 2001, pp. 16-17.

36 Resolución aprobada, por la Asamblea General, A/RES/60/147, consultada en http://daccess-dds-ny.un.org/doc/UNDOC/GEN/N05/496/45/PDF/N0549645.pdf?OpenElement

${ }^{37} \mathrm{Cfr}$, Hernando Valencia, "Víctimas de violaciones graves de los derechos humanos" en

Rafael Escudero Alday (coord.), Diccionario de la memoria histórica, Madrid, Catarata, 2011, pp.107-111.
} 
El contenido de la Resolución 60/147 establece, primordialmente, el sentido de la debida justicia a todas las víctimas de todas las violencias; pues dispone en su Artículo $8^{\circ}$ que "se entenderá por víctima a toda persona que haya sufrido daños individual o colectivamente, incluidas lesiones físicas o mentales, sufrimiento emocional, pérdidas económicas o menoscabo sustancial de sus derechos fundamentales, como consecuencia de acciones $u$ omisiones que constituyan una violación manifiesta de las normas internacionales de derechos humanos o una violación grave del derecho internacional humanitario". ${ }^{38}$

Asimismo, otro aspecto relevante en la Resolución que comentamos, lo constituye el Artículo $11^{\circ}$, donde señala que los derechos de las víctimas son tres principales: el acceso igual y efectivo a la justicia; la reparación adecuada, efectiva y rápida del daño causado; y, el acceso a información pertinente sobre las violaciones y los mecanismos de reparación. La cuestión de la reparación a las víctimas tiende a conformarse en un principio que transforme todo el sistema jurídico internacional; la reparación del daño a las víctimas deberá ser "plena y efectiva", resultado de la intervención de cinco garantías básicas: la restitución, la indemnización, la rehabilitación, la satisfacción y las garantías de no repetición.

De forma breve, se puede señalar que la restitución de las víctimas tiene el objetivo, según el caso, del restablecimiento de la libertad; el regreso al lugar de residencia; la reintegración en el empleo; o la devolución de bienes. Por su parte, la indemnización evoca un sentido de resarcir el daño físico o mental; la pérdida de oportunidades; los daños materiales y la pérdida de ingresos; los perjuicios morales y los gastos legales y médicos. A su vez, la rehabilitación de las víctimas consiste en la atención médica y psicológica y los servicios jurídicos y sociales. En lo que respecta a la satisfacción, consiste en medidas como la cesación de las violaciones continuadas; la verificación de los hechos y la revelación pública de la verdad; la búsqueda e identificación de las personas desaparecidas; el restablecimiento público de la dignidad y reputación de las víctimas; la petición pública de perdón con la aceptación de las responsabilidades correspondientes; entre otras. Finalmente, las garantías de no repetición implican el fortalecimiento de la independencia y la imparcialidad de la justicia; la prevención de los conflictos sociales y la reforma de las leyes violatorias de los derechos humanos y del derecho internacional humanitario, entre otras.

La Resolución constituye el instrumento legal más avanzado del derecho internacional respecto de las víctimas y sus derechos correspondientes. Pese a su riqueza, contrastable vis a vis con la gran mayoría de los Códigos penales y procedimentales de los Estados nacionales, la Resolución en sus dimensiones conceptuales y culturales aparece -todavía- restrictiva y con insuficiencias, al mantenerse en el plano unidimensional del derecho, lo que redunda en una limitación y sujeción respecto del criterio decisivo de la perspectiva legal, en el que la victimización se reduce, en última instancia, a ser sujeto pasivo de un delito tipificado. Fuera de esa constricción, a final de cuentas, premisa fundamental de la Resolución, la noción de víctima se debilita y desdibuja.

\footnotetext{
${ }^{38}$ Ver Resolución 60/147, Ob. Cit.
} 
Para una teoría contemporánea de los derechos humanos y, sobre todo, para la defensa y promoción de los mismos, esa definición de víctima, con todo y los elementos novedosos y positivos que posee, no deja de ser insuficiente de cara a las nuevas circunstancias y retos impuestos por el momento actual.

En paralelo e íntimamente ligado con la definición explícita que provee la Resolución, pero ofreciendo el contexto discursivo y testimonial exigido como condición necesaria para su formulación (y de la totalidad de los instrumentos y/o leyes referidos a las víctimas) cabe señalar, como imprescindible el abordaje del sufrimiento en cuanto tal y -más modernamente- de la distribución del sufrimiento en las sociedades. El sufrimiento de las víctimas ha sido, primordial y permanentemente a lo largo de la historia, asumido por las teodiceas. Se trata de discursos orgánicamente vinculados a las sistematizaciones de las creencias religiosas. ${ }^{39}$

La centralidad de las teodiceas radica, en tanto teorías ético-regulativas dentro de las sociedades, en haber elaborado explicaciones y justificaciones respecto sobre todo de la injusta distribución del sufrimiento. El nervio de su argumentación consiste en la metamorfosis del dolor y sufrimiento personales en una cuestión que debe asumirse y compartirse colectivamente. La preocupación central de los discursos religiosos acerca del dolor consiste, paradójicamente, no en evitar el sufrimiento sino en cómo sufrir del mejor modo posible.

La antropología social y la sociología han sido las disciplinas sociales que han buscado comprender, en sentido moderno, secular, el sufrimiento; cuál es su sentido, si es que lo tiene. Dos son los puntos de referencia clásicos a este respecto. Émile Durkheim $(1912)^{40}$ lo entiende como una pedagogía; aprender a sufrir el dolor como precio para la pertenencia grupal. Por otro lado, es clásico el estudio de Max Weber (1921) ${ }^{41}$; en el contexto de la racionalización y sistematización de las creencias religiosas, propias del complejo proceso de secularización, que ayudan a explicar la injusta distribución del sufrimiento en el mundo y determinan, en consecuencia, el conjunto de los comportamientos prácticos; la tesis radica en que el sufrimiento aparezca como necesario para una teleología de la vida social. De ese modo, el sufrimiento resulta funcional a la constitución de los Estados nacionales como comunidades morales.

El discurso contemporáneo de los derechos humanos, en tanto parte y momento integrante de la evolución de las ciencias y las disciplinas sociales contemporáneas, no sólo se ha conformado como parte activa de la desconstrucción de los relatos de integración y consuelo del sufrimiento de matriz religiosa (como lo son las teodiceas), funcionales ala operación y reproducción de las sociedades, sino, que el discurso de los derechos humanos puede (y debiera), incluso, abrirse y desarrollarse a fin de servir como

39 Veena Das, Sujetos del dolor, agentes de dignidad. Universidad Nacional de Colombia/Pontificia Universidad Javeriana, Bogotá, 2008. p. 439.

40 Émile Durkheim, Las formas elementales de la vida religiosa, Editorial Akal, Barcelona, 1982.

${ }^{41}$ Max Weber, Ensayos sobre sociología de la religión, Tomo I, Taurus, Barcelona, 1998. Ver también, Max Weber, Sociología de las religiones. La ética protestante y el espíritu del capitalismo, edición crítica de Francisco Gil Villegas, Fondo de Cultura Económica, México, 2003. 
un cuerpo de escritura, irreductible a la integración estatal, que permita que el dolor se exprese en él. Se ha planteado como un empeño crítico propio de los derechos humanos ante el sufrimiento de las víctimas ${ }^{42}$ tensar su potencia para entenderse a sí mismo y ofrecer espacio para ser -dicho sea defectuosamente- como una modalidad nueva de teodicea secular (ya no religiosa).

\section{5.- Teoría crítica, derechos humanos y obstáculos epistemológicos a una noción crítica de víctima}

Las ciencias sociales en su conjunto y los derechos humanos, en su entendimiento complejo, como proyecto teórico y práctico, esto es, como discurso de un conjunto de prácticas multidimensionales (resistencia, emancipación, regulación y crítica propiamente dicha) son expresión de una subjetividad de conocimiento que proviene de la propia práctica; un saber práctico derivado de su propio comportamiento objetivo. Se trata, en un primer momento, propiamente gnoseológico, de un sujeto que investiga lo que no conoce y enfrenta obstáculos a su conocimiento (obstáculos epistemológicos, los ha denominado Gaston Bachelard). ${ }^{43}$

En esa lógica, propia de la teoría crítica $^{44}$, el sujeto de conocimiento se construye por la vía de la (des)construcción del objeto; se constituye el sujeto mediante la crítica (superación de los obstáculos), procedimiento que construye al objeto susceptible de conocimiento. En consecuencia, comprendemos lo real, no partimos de lo real (de ahí la importancia del lugar de la víctima como punto de partida metodológico). Partimos del error (la comprensión de su sentido, su finalidad), del sufrimiento, de la injusticia, por el camino negativo hacia la dignidad vulnerada; en ese sentido es que se habla de una primacía epistemológica del error.

Asumir esa primacía teórica del error conduce a la rectificación, la que se conforma y afirma como la base del saber. Es una vía de retroceso para el avance; permite dar a la razón, al conocimiento, motivos para evolucionar. El discurso crítico acumula y rectifica, se aproxima y retrocede, nunca arriba al conocimiento completo, procede por aproximaciones sucesivas, des-construye, es decir, no agota los significados de lo que pretende conocer (comprender y/o explicar), asume la imposibilidad fatal de establecer sentidos inequívocos entre las palabras y las cosas. La teoría crítica sabe de la imposibilidad del conocimiento pleno y final ("la totalidad es no lo no verdadero", sentenciaba Adorno $^{45}$ ) e, incluso, del conocimiento rigurosamente científico -bajo el modelo de las ciencias naturales- de la historia, la sociedad y la cultura; escepticismo radical que -sin embargo- fecunda el saber respecto de la comprensión de

\footnotetext{
${ }^{42}$ Veena Das, op. cit. p. 439.

43 Gaston Bachelard, El nuevo espíritu científico, México, Nueva Imagen, segunda edición, 1985; ver también Gaston Bachelard,La formación del espíritu científico, Siglo XXI, vigésimo tercera edición, 2000.

44 Max Horkheimer, "Teoría tradicional y teoría crítica", en Teoría Crítica, Amorrortu, Buenos Aires, 1968, pp. 223-271.

45 Theodor W. Adorno, Mínima moralia, Caracas, Monte Ávila editores, 1975, pp. 53.
} 
paradigmas y síntomas de los fenómenos que pueblan la vida del mundo y de los sujetos que habitan la historia.

Este breve rodeo, que busca indicar una actitud de método, en el sentido de la vieja teoría del conocimiento, pondera cierta inevitabilidad (y por tanto su idoneidad) del acercamiento negativo, crítico, a los objetos sociales, a las prácticas y las interrelaciones entre los sujetos; deja ver la fuerte utilidad funcional que el concepto de víctima en su uso epistemológico y heurístico ofrece al discurso de los derechos humanos, en particular; pero también al derecho y al conjunto de las disciplinas sociales, en general.

Conviene tener presente que el concepto de víctima es trascendental en la teoría clásica de los derechos humanos y en la motivación ética y política de su reformulación refundacional (luego de terminada la Segunda Guerra Mundial). Es más, se puede afirmar, como una referencia teórica insustituible, la constelación conceptual que compone la relación entre las nociones víctimaviolencia-dignidad.

Complementariamente, para un empeño como es el la construcción de un concepto de víctima renovado críticamente, resulta metodológicamente significativo asumir y desarrollar las consecuencias teóricas pertinentes de cómo es que la idea de víctima juega el papel de un concepto pivote, un gozne de articulación de índole ético y epistemológico y, por tanto, la carga y la potencia teórica bidimensional de ser un concepto apto para la comprensión y pertinente para las explicaciones. Ese entendimiento de la víctima, como hemos visto, supone un avance para producir una idea adecuada a las necesidades contemporáneas de un discurso crítico de los derechos humanos.

En breve, podemos decir que el objeto del conocimiento social, las prácticas, las relaciones, los hechos sociales, son artefactos; resultado de la actividad intelectual del sujeto $\left(\mathrm{Kant}^{46}\right)$, algo construido, producido por la práctica material y espiritual del sujeto $\left(\mathrm{Marx}^{47}\right)$; que, además, es resultado de un proceder negativo, crítico, que induce a la rectificación y al avance cognoscitivo por la vía del ensayo-error (Horkheimer ${ }^{48}$ ). Se construye un modelo abstracto, un tipo ideal $\left(\right.$ Weber $^{49}$ ), que conforma la pre-condición e informa de los prerequisitos y preliminares de la práctica científica; modelo construido que no sirve para fijar el conocimiento, sino que constituye la condición de posibilidad para su desconstrucción, a semejanza del tipo ideal en su aproximación correctiva y/o desconstructiva hacia la realidad.

El modelo es pues un obstáculo epistemológico necesario, en el sentido y de manera análoga a como la definición dominante de víctima sirve como el modelo a ser criticado, desconstruido; el espacio de error que reclama rectificación, el objeto de negación del restrictivo concepto juridicista de víctima y sus contenidos sacrificiales. La crítica a la noción dominante de víctima

\footnotetext{
${ }^{46}$ Inmanuel Kant, Critique of Pure Reason, Allen W. Wood (ed.) Cambridge University Press, 1999.

${ }^{47}$ Karl Marx, "Tesis sobre Feuerbach y Ludwig Feuerbach" y "El fin de la filosofía clásica alemana", ambas en Karl Marx y Friederich Engels, Obras Escogidas (2 vols.), Moscú, Editorial Progreso, 1981.

${ }^{48}$ Max Horkheimer, op. cit, pp. 223-271.

${ }^{49}$ Max Weber, Ensayos sobre metodología sociológica, Buenos Aires, Amorrortu, 1993.
} 
resulta un pre-requisito indispensable para el paso a una construcción de una otra noción, crítica, abierta, flexible y funcional de víctima.

Se sabe, los conceptos son fragmentarios de la realidad. El concepto de víctima también lo es. A ese respecto, el trabajo de crítica y rectificación ha de ser permanente, entre otras razones y sobresalientemente, puesto que las modalidades de victimización, ejercicios de violencia y vulneración de la dignidad de los individuos, son históricamente cambiantes, condicionados por las variantes de comportamiento y de relaciones sociales y políticas específicas. Además, las cautelas críticas respecto a la noción de víctima debieran de extremarse, toda vez que pensar a las víctimas de inmediato convoca cargas emocionales, sentimientos de culpa y piedad, identificaciones auto-conmiserativas, efusiones de auto-exculpación e impulsos de venganza como reacciones múltiples y contradictorias ante la pulsión sacrificial de sus significados.

La noción de víctima es -como hemos visto- una noción vaga, cargada de polivalencia semántica y de polisemia cultural. De entrada, estimula aproximaciones intuitivas y favorece los prejuicios, fuentes principales de los obstáculos epistemológicos. El modo de trabajo o procesamiento racional sobre el concepto ha tenido tradicionalmente la deriva dominante del derecho, de manera que la noción de víctima con mayor y mejor carga intelectual resulta ser predominante y unidimensionalmente jurídica. La parafernalia técnicoadministrativa relativa al interés pragmático, propio del saber jurídico, ha resultado ser velo y complemento de los significados de sacrificio y resignación inherentes a la idea de víctima, contenidos arcaizantes y de corte teológico.

No obstante, son de reconocer, por supuesto, los esfuerzos recientes de la justicia de transición o transicional, así como de corrientes del derecho penal por resituar a la víctima en el proceso de impartición de justicia e insistir en modos de reparación del daño integrales. Pese a ello, las limitantes y parcialidades de las consideraciones sacrificial-juridicistas acerca de la víctima tienen como consecuencia una indefinición respecto de las determinaciones políticas de calificación respecto de quienes son víctimas y los que no lo son, así como en relación a los riesgos de credibilidad que la autodesignación de las víctimas -a partir de la queja o de la protesta- suponen, no digamos la frustrante consideración de las víctimas como sujetos disminuidos y menospreciados cuyo reclamo de reconocimiento se suspende en la mera constatación del espectáculo del sufrimiento.

Así, la correlativa compasión que la deshumanización de las víctimas expresa, la piedad y/o indignación generada por la constatación de su dignidad vulnerada, los sentimientos y emociones (su impacto intelectual) provocados por la injusticia son útiles y acaso indispensables para generar el impulso moral detonante de la acción crítica, pero resultan improcedentes y hasta negativos para ensayar una fundamentación ética de los derechos humanos.

Por todo ello, el discurso de los derechos humanos debe proceder a una recepción crítica -de rectificación y remoción de los obstáculos epistemológicos- de la noción modélica dominante de víctima como condición de posibilidad para la construcción de un concepto abierto, complejo, funcional y suficiente de víctima, atento a las alteraciones que las condiciones sociales, políticas, económicas y culturales contemporáneas que, mediante nuevas y 
alteradas formas de violencia, vulneran y demeritan los derechos humanos de los individuos y su dignidad.

Las consecuencias prácticas y políticas de un concepto críticamente refuncionalizado de víctima podrán redundar en un mejor control de las implicaciones prácticas de los acontecimientos donde se instauren significados, emplazamientos y luchas de y por el reconocimiento de las víctimas. Pero este fortalecimiento de las políticas de derechos humanos y de dignificación de los individuos violentados y vulnerados en su dignidad (ultrajados o restringidos en sus libertades, negada o disminuida su igualdad) implica una superación del significado de postración y menoscabo inherente a la noción dominante de víctima, resultado del sufrimiento que le ha sido infringido por las diversas modalidades de violencia imperante.

Habría que añadirla cuestión, teórica y filosóficamente crucial, acerca de si la perspectiva de la víctima y su correspondiente concepto crítico es pertinente y efectivamente plausible en relación a una fundamentación ética contemporánea (no religiosa o metafísica) del discurso de los derechos humanos. Pregunta clásica y motivada en y desde el momento mismo de la refundación de los derechos humanos (1948-52) posterior a la Segunda Guerra Mundial.

La crítica reflexiva y práctica respecto al concepto de víctima lleva a un replanteamiento respecto de ideas y prácticas asociadas con ella. Indefensión, sometimiento, debilidad, reconocimiento negativo como meras víctimas, al final, variadas formas de menosprecio, redundan en un bajo potencial de protesta, una restricción de sus alcances organizativos, convocatorias de solidaridad compasiva, manipulaciones políticas y facilidades al chantaje de las víctimas indirectas: la noción convencional de víctima se limita al umbral de la queja victimante y no alcanza la proclama de la protesta, ni al discurso teórico y práctico crítico y transformador de su condición adolorida y subordinada.

Amén de todos esos elementos, que son intrínsecos, inmanentes, al concepto de víctima, hay que considerar los factores extrínsecos, trascendentes, tales como: el exceso de violencia y su correlativo plus de sufrimiento socialmente producido, así como la consecuencia de una multiplicación de potenciales víctimas en las actuales circunstancias de las sociedades de riesgo contemporáneas. Estos factores extrínsecos, que configuran el entorno 0 contexto que induce (potencia o estimula) un exceso de sufrimiento social inasimilable, inducen perentoriamente la necesidad de procurar un concepto de víctima complejo, amplio, dinámico y funcional para lidiar mejor (procesar adecuadamente) esa sobrecarga de violencia sobre la sociedad.

Esos obstáculos epistemológicos principales para la producción de un concepto crítico de víctima, en el sentido arriba referido, son -en este primer momento crítico- distinguidos y enunciados bajo la determinación convencional y dominante del concepto de víctima, sacrificial-juridicista, con el que habitualmente trabaja el discurso de los derechos humanos.

El concepto dominante de víctima es formalmente juridicista y sacrificial en cuanto a sus contenidos. Las determinaciones de sus significaciones sacrificiales y/o de auto-inmolación aparecen veladas por determinaciones seculares. Ellas son: (1) el carácter político en la determinación de la víctima; (2) la auto-designación de la víctima y su correlato de credibilidad; (3) el cuerpo sufriente de la víctima como el espacio del menosprecio. Esas determinaciones 
de la idea prevaleciente de víctima enmascaran contenidos de exclusión y marginalidad, menosprecio y afán de credibilidad, así como auto-conmiseración y bajo potencial de protesta. Procedamos, en esta primera aproximación, a su delimitación y enunciación en tanto que obstáculos epistemológicos.

\section{6.- Juridicismo y víctima}

Ya se ha observado que la noción de víctima, desde la perspectiva jurídica, resulta sumamente restrictiva. Esto así, en virtud de que dicho concepto se inscribe, exclusivamente, sea en la afectación a un bien jurídicamente tutelado o que el comportamiento del victimado se encuentre tipificado por la ley. Asimismo, el estudio y la complejidad de la víctima parece no tener relevancia en las definiciones de corte jurídico, con lo cual la distinción entre la víctima y la no-víctima se reduce tan sólo a la tipificación de una conducta agresora signada en la ley penal.

El reduccionismo de la noción jurídica de víctima se basa en la estrecha relación criminal-víctima; lo que soslaya las posibilidades de una definición más fáctica que jurídica, esto es, que la víctima no sea solamente delimitada por un código penal. Resulta necesario repensar la noción de víctima en sentido contrario a la de víctima "codificada" por la actividad criminal, situarlo más allá del entendimiento restrictivo de la propia noción jurídica de víctima y su frágil acepción en tanto víctima de un delito.

Esto impele a asumir una postura crítica relativa a la visión unilateral y dominante de víctima, regida por el derecho (amén de toda una semántica vinculada al sacrificio, las penas y el sufrimiento); un planteamiento teórico a contracorriente de lo establecido y dominante sobre la noción de víctima.

Resulta frecuente, que los problemas teóricos de la noción de víctima se deslicen al plano de las determinaciones de un delito, dando preminencia al interés técnico-formal; bajo la insistencia de una noción jurídica de víctima caben las consecuencias más ostensibles como el formalismo, el burocratismo, aunado, a un creciente manejo cuantitativo-estadístico de las mismas así como el debilitamiento de las modalidades pro-activas de defensa y promoción de sus derechos vulnerados. ${ }^{50}$

No obstante, en tiempos recientes se han abierto y desarrollado discusiones y debates alrededor de los alcances, potencialmente emancipatorios, implícitos en la noción de víctima; por un lado, se prefiere evitar el término víctima con base en la necesidad de las personas de no ser estigmatizadas en función de sus vivencias y de desestimular la posición pasiva que se produce, sobre todo si la persona es receptora de asistencia psicológica o social por esa misma condición. Y por otro lado, se defiende el uso de la designación de víctima como una forma de resistencia activa, reconociendo y reconociéndose no solo en el sufrimiento, sino también y especialmente en la condición de actores políticos -por tanto, sujetos de derechos-, en procurar que se haga justicia, se reparen los daños ocasionados y se garantice la no repetición de las violaciones. En el seno del derecho penal se ha desarrollado una cultura reconstructiva que atañe prioritariamente a las víctimas, asimismo, la justicia de

\footnotetext{
${ }^{50}$ Ver Pierre Bordieu, Lección inaugural, Barcelona, Anagrama, 2002, p.13
} 
la transición o transicional ha ubicado a las víctimas como una de las variables centrales de los procesos de cambio de régimen autoritario a otro democrático.

Finalmente, cabe apuntar que una de las cuestiones centrales de delimitación del espacio victimal y, por ende, de la designación de víctima, lo constituye la justicia, la justicia como tal. Se trata de una de las tensiones más radicales inherentes a la historia humana, en general, si bien de un modo más explícito y denodado en la modernidad capitalista, enfáticamente desde finales del siglo $X X$ y lo que va del presente siglo, a saber: la tensión ley/justicia. ${ }^{51}$ Cada vez con mayor fuerza, el tema relevante y esencial alrededor de la víctima suele ser la existencia de leyes que victimizan a la víctima, una doble victimización. Esto es, un sujeto puede ser victimizado por la propia ley; este hecho cuestiona el contenido justo de la ley y con ello se abandona la pretensión a priori de que toda ley, por el hecho de serlo, sea justa. En este sentido, el tratamiento crítico de la noción dominante de víctima resulta implosivo de la ecuación -falsamente resuelta- entre justicia y ley.

\section{7.- Politicidad de la determinación de la víctima}

¿Quién define a la víctima? La víctima debe ser designada, deber ser mostrada como tal. ¿Quién es la verdadera víctima; quiénes son ellas? ¿Quién las designa? ¿Bajo qué criterios?

Ante un atentado terrorista los medios de comunicación hablan de víctimas; pero los muertos en un bombardeo o en un enfrentamiento entre las fuerzas armadas del orden y los criminales no son calificados de víctimas; son otra cosa. Se les denominan daños colaterales, resultan ser excedentes de lo verdaderamente importante que, por supuesto, no son ellos, esos muertos, pese a todo. El calificativo, la designación de esos muertos en tanto víctimas se ha extraviado, les ha sido escamoteado.

En nuestro mundo globalizado y a partir de ciertas coordenadas útiles para la adscripción, un occidental sacrificado en una acción terrorista es víctima; un afgano o un palestino muerto en alguna acción militar ya es menos víctima; los muertos en un casino de Monterrey incendiado por criminales como represalia son víctimas, pero la familia abatida en un retén militar en una carretera del Estado de Coahuila, en México, son daños colaterales (no obedecieron la orden de detenerse...).

Así pues, hay de víctimas a víctimas, vidas que valen más que otras, dignidades más vulnerables que otras o con menos consecuencias. Es una cuestión de injusticia o justicia, según la perspectiva; pero que va más allá del territorio referente al cumplimiento de la ley y la adscripción de las víctimas respecto de su articulación con algún delito tipificado. En todo caso, atañe a la cuestión de la definición del concepto de víctimas y, por tanto, repercute en el discurso de los derechos humanos.

La pregunta que se impone es: ¿quién es la víctima?, ¿quién es considerado víctima? Lo primero es admitir que la idea de víctima supone una visión política de la situación; que ciertas prácticas, criterios, determinaciones y

\footnotetext{
${ }^{51}$ Cfr. Michel Foucault, Vigilar y castigar, op. cit. pp. 216-218
} 
valores intervienen y condicionan las definiciones de víctima y las adscripciones respectivas para un individuo o un grupo de individuos. Es desde el interior de una política que se decide quién es verdaderamente la víctima y, en consecuencia, el que políticas diferentes tienen víctimas diferentes.

Esta determinación de la política o de las políticas respecto de las víctimas, en relación a quienes son víctimas y quienes pueden y/o deben ser considerados víctimas, constituye, a todas luces, un obstáculo epistemológico para la producción de un concepto idóneo y funcional de víctima. La consecuencia inmediata radica en que la noción de víctima en su determinación política inicial no es un punto de arranque satisfactorio puesto que víctima es un término políticamente variable.

A este polo ante cuya fuerza de atracción política sucumbe la noción ingenua de víctima, sin especificidad política propia, habría que oponer desconstructivamente- el significado político radical intrínseco de los derechos humanos. Si la víctima asume e interioriza como proyecto para su pleno reconocimiento a los derechos humanos, entonces, estará dotada de instrumental político apto para resistir los criterios de designación política de las víctimas. Esto es así, en virtud de que resulta inverosímil recusar la determinación política en la conformación del concepto de víctima (en particular), así como en el diseño e implementación de las políticas de derechos humanos (en general), con la noción dominante de víctima, despolitizada e indefensa. El asunto decisivo radica en la pregunta de si se puede predicar de los derechos humanos un sentido político en sentido estricto.

En mi opinión, la respuesta es que sí. Los derechos humanos son, efectivamente, derechos; pero son primordialmente humanos. Son: proyecto teórico-práctico, un movimiento político y jurídico humanista, discurso de un saber práctico, multiplicidad de prácticas multidimensionales, repertorios de acciones estratégicas y tácticas. En suma, los derechos humanos son, en su radicalidad, prácticassociales que precipitan acontecimientos políticos.

Para Alain Badiou, el acontecimiento surge desde el trasfondo invisibilizado de una situación. Desde aquello que, en la lógica hegemónica del poder (relación de dominio), no debería existir, pero que se revela de una manera súbita e impredecible. De tal forma que, un acontecimiento es "una singularidad universal" ${ }^{2}$; un hecho que, aunque esté anclado en una historia particular, implica algo válido para todos.

Las situaciones generadas por prácticas de resistencia al abuso de poder, prácticas emancipatorias de afirmación de libertades, reivindicación política activa del derecho a tener derechos, prácticas regulatorias para garantizar los derechos (las libertades) alcanzados, prácticas discursivas que niegan críticamente los abusos y las vulneraciones a la dignidad de los individuos y/o que proclaman los valores de la libertad, la igualdad y la solidaridad que conllevan el poder de instaurar y emplazar acontecimientos políticos; esto es acontecimientos que alteran y modifican las relaciones de dominio prevalecientes, emergencia de lo no domesticable por las convenciones y las políticas institucionalizadas del statu-quo.

\footnotetext{
${ }^{52}$ Alain Badiou, El ser y el acontecimiento, Buenos Aires, Ed. Manantial, 1999. p. 43.
} 
El acontecimiento subvierte la hegemonía y/o el sistema de creencias de manera que se vuelve a hacer palpable el vacío primordial de la condición humana, su falta de metas u objetivos predeterminados, el hecho de que el sentido resultará siempre una construcción inter-subjetiva. Pero junto con el vacío aparece una verdad susceptible de ser universal, un camino potencialmente abierto a todos. Los derechos humanos contienen la potencialidad para expresar, en la actualidad, esa, una, universalidad posible a partir de la diferencia radical de los victimizados.

Lo político de los derechos humanos -y eventualmente una política derivada y un proyecto de los derechos humanos- resulta una especie de invención instaurada a través de movimientos inéditos, lo que hemos llamado con Badiou, el acontecimiento; esa instancia sin planes previos que lo significa como tal, donde las victimas se pronuncian. Una política de la presentación que establece una relación no representativa con las instancias de poder; un proyecto implícito de justicia que no es un programa a futuro sino un acto presente. La igualdad política, entendida como un tipo de justicia ${ }^{53}$, no es lo que se desea o se proyecta: es lo que se declara al calor del acontecimiento, aquí y ahora, como lo que es y no como lo que debe ser; tampoco es un programa, la justicia es la calificación de una política igualitaria en acto. Aquí la escena de lo esencialmente político de los derechos humanos, de su afirmación práctica como idea.

También es cierto que se puede hacer política con los derechos humanos, se les puede instrumentalizar y utilizar para objetivos ajenos, políticamente aceptables o condenables, al servicio de los de arriba o los de abajo, por la perpetuación del statu quo o su alteración, justicieros (igualitarios) o injustos (para agudizar las desigualdades). No obstante, esas instrumentalizaciones políticas, no eliminan el sustrato político inmanente propio de los derechos humanos al que nos hemos referido.

Ese sustrato, lo intrísecamente político del proyecto y el discurso de los derechos humanos, radica en que lo específico y común de esas múltiples prácticas de resistencia, reclamo, imposición y emplazamiento de actos, hechos o acontecimientos de tensión de la correlación de fuerzas, conlleva e implica exigencias de reconocimiento. Es el carácter de emplazar prácticamente relaciones de poder en términos de reconocimiento, de lucha por el reconocimiento, lo que define lo esencialmente político de los derechos humanos. $^{54}$

Al decir: “¡no!, ¡basta!, ¡así no!, ¡no más...!”, los individuos resisten, pero también reivindican, emplazan, estatuyen una exigencia de reconocimiento respecto del otro; del que violenta, abusa, explota...¿ ¿Reconocimiento de qué? De la dignidad, responde el movimiento y el discurso de los derechos humanos, afirmación de la alteridad en pie de igualdad y por virtud de ser sujetos libres.Reivindican emancipación, libertades-derechos-, regulaciones, garantías

\footnotetext{
53 Alain Badiou, Compendio de metapolítica, Buenos Aires, Prometeo Libros, 2009, pp. 85-96.

54 Se haría necesario para el argumento la pertinencia de la distinción entre lo político y la política; no es aquí el momento (ni hay el espacio) para tal desarrollo. En ese sentido ver: Claude Lefort, La incertidumbre democrática. Ensayos sobre lo político. Anthropos, España, 2004; y Chantal Mouffe, El retorno de lo político, Barcelona, Paidós, 1999.
} 
(de cara al Estado); se plantan libremente, en pie de igualdad, fieramente, exigiendo reconocimiento...con dignidad, se dice. Dignidad que sólo es discernible, constatable y afirmable por vía negativa: ante su denegación, el abuso, las violencias que vulneran la dignidad; esto es, ante la negación de las libertades y la desigualación de los iguales. ${ }^{55}$

Desde esa radicalidad, relativa al carácter político intrínseco de los derechos humanos, es que resulta adecuado suponer que estarían en condiciones de posibilidad desobreponerse al politicismo inherente a la calificación de las víctimas y -asimismo-coadyuvar al diseño e instrumentación de una política, entendida como disciplina ante las consecuencias del acontecimiento, nueva victimología en clave de derechos humanos.

La noción crítica de víctima, en tanto que elemento apto para coadyuvar a una fundamentación ética de los derechos humanos, asume un papel trascendente en la lucha de sujetos que reivindican aspectos no reconocidos de su identidad, por la vía de la conciencia de haber sufrido una injusticia. Es a partir de este momento que la víctima-al igual que los maltratados, excluidos o despreciados, diversos grupos victimizados que han experimentado formas denegación del reconocimiento- no sólo sufren a partir del menosprecio de su condición, sino que, cabe advertir, también el menosprecio en sí mismo puede producir sentimientos que motivan, que impelen, a devenir en sujetos de las luchas por reconocimiento.

Situar el concepto de reconocimiento, con su evidente potencial crítico, en la contribución de un concepto crítico de víctima (complejo, abierto, dinámico, funcional), significa asumir la centralidad del conflicto bajo una función positiva (creativa) de integración social, a condición de que se le deje de ver de un modo limitado y negativo, como ha sido el caso desde la perspectiva teórica dominante.

Las luchas de reconocimiento, históricamente, han generado la institucionalización de ciertas prácticas sociales que evidencian el pasaje de un estadio moral a otro más avanzado - un aumento de la sensibilidad moral, señala Honneth. ${ }^{56}$ La lucha de los grupos sociales por alcanzar formas cada vez más amplias de reconocimiento social se convierte, muta, en una fuerza estructurante del desarrollo moral de la sociedad.

Así, en dicha perspectiva, la lucha social no puede explicarse sólo como resultado de una lucha entre intereses materiales en oposición sino también como consecuencia de los sentimientos morales de injusticia. Es lo que define Honneth, como una gramática moral de los conflictos sociales. ${ }^{57}$ La víctima, cuya visibilidad se posibilita a través del sufrimiento, se constituye primordialmente en esa imagen de injusticia.

\footnotetext{
55 Materialización del proceso de exclusión, estudiado ejemplarmente por Foucault y del proceso de la desigualdad, paradigmáticamente analizado por Marx.Para una presentación sintética de esos procesos en contexto de derechos humanos, ver Alan Arias, "Globalización y debate multicultural. Un nuevo imperativo contemporáneo", Revista Derechos Humanos México, México, núm. 12, 2008.

${ }^{56}$ Axel Honneth, Reconocimiento y menosprecio. Sobre la fundamentación normativa de una teoría social, Buenos Aires, Katz editores, 2010. p. 37.

${ }^{57}$ Axel Honneth, The Struggle for Recognition. The Moral Grammar of Social Conflicts, Cambridge, The MIT Press, 1995.
} 
El pensamiento latinoamericano de la liberación, heredero mediado de la teología de la liberación, a la que ya nos hemos referido, ha ensayado una suerte de politización del discurso religioso de los derechos humanos: historización del sujeto oprimido, el sujeto sufriente que descubre su lugar en la historia y lo lleva a la acción en defensa de los derechos humanos para cambiar el sistema jurídico existente. Con esa perspectiva, ha adelantado elementos críticos para situar un rol determinante para las víctimas; aspectos relevantes, muchos de ellos complementarios y rescatables desde una perspectiva abierta de la teoría crítica, no obstante la inveterada inclinación juridicista dominante en América Latina.

La lucha por el reconocimiento de nuevos derechos humanos a través de los diversos movimientos sociales, históricamente determinados, ha sido, principalmente, descubierto por las víctimas. Las luchas y reivindicaciones de las víctimas lograron traducirse en nuevos derechos, un nuevo sistema de derecho. Enrique Dussel señala que "la negatividad material (la miseria, el dolor, la humillación, la violencia sufrida, etcétera) indica al "sin-derecho" como un "hueco" negro dentro del "sistema del derecho". ${ }^{58}$ La lucha por el reconocimiento de dicho territorio victimal "en-negativo", es el origen histórico de los nuevos derechos del nuevo cuerpo de derecho.

Dussel señala con respecto al proceso de victimización, que existen ciudadanos que pueden ser también víctimas cuando son excluidos nointencionalmente por el derecho, excluidos del "Sistema del Derecho" como lo denomina Dussel. Esto es, existen ciudadanos y colectividades con conciencia de ser sujetos de nuevos derechos, toda vez que sufren algún tipo de rechazo con lo cual se experimentan a sí mismos como víctimas. Estas víctimas son la mujer en la sociedad machista, las razas no blancas en la sociedad racista occidental, los homosexuales en las estructuras heterosexuales, las clases explotadas por una economía del lucro, los inmigrantes, etcétera.

De forma tal que, las víctimas de un "sistema del derecho vigente" son los "sinderechos" (o los que todavía no tienen derechos institucionalizados, reconocidos, vigentes) ${ }^{59}$ Desde dicha perspectiva, de manera coincidente con la teoría crítica, los derechos humanos son históricos, determinados por su especificación histórica, en virtud de la conciencia ético-política de los "nuevos" movimientos sociales que luchan por el reconocimiento de su dignidad negada. La dialéctica de los derechos humanos, agrega Dussel, se articula entre el "derecho vigente a priori versus nuevo derecho a posteriori", siendo el nuevo derecho la instancia crítica a posteriori -es decir: histórica- y el derecho vigente el momento positivo, reformable, cambiable.

\section{8.- Víctima y derechos humanos: preliminares de un vínculo orgánico}

Las dignidades vulneradas, los derechos humanos violentados, las relaciones de igualdad y equidad resquebrajadas, las libertadas negadas, refieren a una injusticia. Es más fácil hablar de injusticia de los derechos humanos violentados que de la justicia. La justicia es oscura; la injusticia es clara. Sabemos mejor

\footnotetext{
${ }^{58}$ Enrique Dussel, Hacia una filosofía crítica, Ed. Descleé de Brower, Bilbao, 2011, p. 153.

${ }^{59}$ Enrique Dussel, Op. Cit, p. 151.
} 
qué es la injusticia, pero es mucho más difícil hablar de qué es la justicia. ¿Por qué? Porque hay un testigo de la injusticia que es la víctima. La víctima puede decir: aquí hay injusticia. Pero no hay testimonio posible de la justicia (nadie puede decir, yo soy el justo...). No obstante, el estar de lado de las víctimas (Foucault), ese compromiso moral de defensores, estudiosos, activistas y funcionarios comprometidos con los derechos humanos no resulta fácil. No lo es teóricamente, respecto del discernimiento de quien es la víctima, y, no lo es moralmente en cuanto a la credibilidad y confiabilidad de las maneras de designar a las víctimas (ya hemos visto como es una operación y una racionalidad políticas las que determinan, en primera instancia, quién es víctima y quién no lo es).

Existe una asimetría entre la víctima de la injusticia y la idea de justicia, entre la víctima de una violación a los derechos humanos y el proyecto práctico y discursivo del movimiento de los derechos humanos. La tradicional disonancia entre el derecho, su carácter procedimental y la justicia, su determinación valorativa, explota. Sin olvidar los problemas radicales existentes respecto al testimonio de la víctima y las narrativas del sufrimiento.

Tenemos que la víctima se define a sí misma. La víctima se presenta como tal, como víctima; el asunto es devastador, no sólo por el dolor y la pulsión compasiva que provoca; es un problema de conocimiento que se degrada en una cuestión de credibilidad. Va a ser necesario que le creamos a la víctima. Que su queja sea creíble para completar el círculo de reciprocidad necesario para el reconocimiento de su carácter de víctima. En tal caso, la noción de víctima se vuelve una cuestión de creencia. ${ }^{60}$ ¿Le crees a quien se presenta como víctima que sí lo es o no? Se estatuye un obstáculo que pone en tensión la creencia con el saber, ese es el callejón sin salida que se deriva de la autodesignación de la víctima.

O si se quiere, se puede plantear en términos de que la injusticia nos va a ser revelada a partir de la presentación de una queja; entonces, la determinación de la injusticia estará ligada a la protesta de la víctima. No obstante, se sabe que hay diversos tipos de queja: la queja neurótica (estudiada por el psicoanálisis), la queja que no plantea la cuestión de la injusticia (el resentimiento en el pensamiento de Nietzsche, por ejemplo); quejas que no crean ninguna justicia. ${ }^{61}$ Con frecuencia, la queja se agota en una demanda al otro y no es realmente un testimonio de injusticia.

Lo que va validar o incrementarla credibilidad de la víctima habrá de ser la calidad de su queja, de su reclamo. Así, eliminar el obstáculo implícito en la auto-designación de la víctima lleva al esfuerzo de superar el ámbito de creencia en el que ha quedado emplazada la cuestión del reconocimiento y la identidad de la víctima en cuanto tal. Tendrá que ser probada la idoneidad de la víctima, tendrá que demostrar su carácter de víctima, exhibir las pruebas de su sacrificio, de su sufrimiento, pruebas materiales de la violencia padecida. En ello radica el incentivo, la tentación de mostrar el cuerpo sufriente, el espacio físico del dolor.

\footnotetext{
${ }^{60}$ Alain Badiou, La ética, México, Herder 2004, pp. 45-49, también pp. 31 y sigs.

${ }^{61}$ Alain Badiou, Ob. Cit., pp. 31-32.
} 
Probablemente, la satisfacción de ser reconocido como víctima sufriente por esa vía lo lleve a cierta complacencia respecto a su cuerpo dolorido, incluso, a una amplificación de su vulnerabilidad haciendo el montaje del espectáculo del cuerpo sufriente (de la víctima). Fijación en el cuerpo postrado, yaciente, incompleto, condenado a un reconocimiento menoscabado, en una noción meramente sacrificial de víctima, unilateralmente restringido al sufrimiento.

También hay, como corolario de lo anterior, la víctima que se nos revela por el espectáculo del sufrimiento. Esta modalidad se articula con las insuficiencias e inconsistencias derivadas tanto de la determinación politizada de quién es víctima, así como de las incredulidades que propicia la designación, hecha por sí misma, de la víctima. Aquí la injusticia de los derechos humanos vulnerados es un cuerpo sufriente visible; la injusticia, el espectáculo de las personas sometidas a suplicios, hambrientas, heridas, torturadas.

Este espectáculo induce un gran sentimiento de piedad, de compasión, de amor al prójimo. El camino del reconocimiento de ser propiamente víctima puede transitar equívocamente por la generación de sentimientos y emociones compasivas. Compasión vinculada a las significaciones sacrificiales y de inmolación asociadas atávicamente a la idea prevaleciente de víctima. Ya Theodor W. Adorno, alertaba a ese respecto.

La crítica de la compasión en Adorno se ubica en el contexto de la crítica más general que realiza a la moral prevaleciente en la sociedad moderna. La labor desconstructiva parte de la propia y constitutiva ambivalencia de la crítica, la crítica de la moral tiene que estar tanto a favor de la moral como en contra de ella. ${ }^{62} \mathrm{La}$ crítica se presenta en un doble frente (teórico-práctico); uno, en tanto crítica de la moral en cuanto tal, el otro, en tanto crítica de la existente realidad inmoral. El tránsito de una crítica a otra, va a develar la presencia de un "impulso moral" hacia la acción, esto es, la agitación ante situaciones insoportables, la indignación ante la injusticia. Asunto clave que la víctima revela. Sin la evidencia del trato inhumano, no existe resistencia frente a la inhumanidad.

Sin embargo, la crítica a la moral y a sus ambigüedades prácticas, apunta Adorno, no quedan eliminadas postulando la compasión como principio moral. La afirmación y aceptación de la compasión y el compromiso derivado con ella, significa solamente la confirmación y aceptación de esa regla de inhumanidad existente en la realidad como algo inmanente e incapaz de distancia en su crítica.

La compasión siempre resulta insuficiente toda vez que supone una separación entre el principio moral respecto de lo social y sus condiciones injustas, transformando a dicho principio tan solo en una convicción privada, mutilando su potencial universalidad; esta es su contradicción inescapable, el ámbito de la compasión es el de la moral individual no obstante que su origen y sustancia es el sufrimiento socialmente producido. La compasión como principio moral respecto de las víctimas del sufrimiento y la injusticia socialmente producidos,

62 Theodor W. Adorno y Max Horkheimer, Dialéctica de la Ilustración, Trotta, 1994, pp. 123 y sigs. Esa modalidad de operación desconstructiva es característica de la teoría crítica que postula -siguiendo a Kant- que la crítica de la razón no es ni será siempre una crítica mediante la razón, sino una crítica ejercida sobre la propia razón. 
conlleva un sentimiento individual que implica una asimetría de quienes son objeto de compasión y el sujeto que la procura (la imposibilidad de un reconocimiento entre iguales); la compasión es, simultáneamente, impotente e ilusoriamente caritativa.

Aunado a ello, otro impedimento para invalidar a la compasión como principio moral, es su significación limitada de identificación compasiva. Pese a que se lograra, aún con las dificultades que implica, una plena identificación con la víctima y su sufrimiento, no podría ser suficiente, dada la acumulación inmensa de sufrimiento anterior, para superar el principio de auto-conservación de quien se compadece del otro (de la víctima), que se mantiene y prevalece sobre la base de un orden injusto.

Debido a ello, es que existe una compasión aceptada por la sociedad y vehiculada institucionalmente con excedentes victímales, con afán de ser descarga emocional y sentimental a las culpas individuales, así como meras compensaciones marginales y excedentes del orden injusto ${ }^{63}$. Por todo ello, la compasión redunda en concesión o pacto con lo malamente establecido $u$ ocurrido. La reivindicación victimal de la compasión termina malamente -a su vez- en complicidad vergonzante con el orden social y su moral establecida, que son los mismos que han dado cobijo y espacio de acción a los victimarios.

Pero si la víctima se reduce a ser expresión sintetizada en el espectáculo del cuerpo sufriente, se podría concluir que la justicia, su construcción referencial a partir de su contrastación ante la injusticia, sería solamente un asunto referido al cuerpo, a la cuestión del cuerpo sufriente, lo vinculado unilateralmente a la herida de la vida. Es un hecho que en la época contemporánea se transforma cada vez más el sufrimiento en espectáculo; ya no sólo el espectáculo imaginario (el cine, la televisión con sus programas de tortura y violencia), sino también en el documento bruto que nos muestra el espectáculo del cuerpo sufriente donde la humanidad es reducida a animalidad; no digamos la multiplicación espectacular del sufrimiento facilitado por el acceso -en tiempo real- a las vulneraciones de la dignidad de hombres y mujeres, obsequiados por los avances tecnológicos.

Por ello es imprescindible recuperar el principio de la inseparabilidad del cuerpo humano de la idea (prácticas humanas de un sujeto orientadas por un proyecto); redefinir el cuerpo mediante el combate a esa forma moderna que es devaluación deliberada de la dimensión del cuerpo, reducido a dos posibilidades: la del cuerpo consumidor 0 el cuerpo sufriente de la víctima. ${ }^{64}$ ¿Se puede fundar una idea de justicia a partir de ese cuerpo espectáculo? La piedad, la compasión, son sentimientos significativos, pero, como se ha visto, no se puede transitar directamente de la piedad a la justicia.

No un cuerpo sin idea, no el cuerpo del esclavo cuya idea pertenece al amo (como en el Manón de Platón). Un cuerpo diferente, como otra cosa que un cuerpo, ligado a algo más que a sí mismo. A través del cuerpo del sufrimiento, la figura de la víctima postrada como soporte (único) de la justicia no caminamos en el sentido de un reconocimiento sostenido por prácticas de

\footnotetext{
${ }^{63}$ Theodor W. Adorno, Mínima moralia, op. cit.

${ }^{64}$ Alain Badiou, Justicia, filosofía y literatura, Homo Sapiens Ediciones, Rosario, 2007, pp. 21 y sigs.
} 
resistencia, emancipación y crítica; no avanzamos en pos de un reconocimiento entre libres e iguales.

Para arribar a la justicia hace falta más que el cuerpo sufriente; se hace necesaria una definición de la humanidad más amplia que la de mera víctima. Que la víctima sea testimonio de algo más que de sí misma. Es necesario el cuerpo, pero un cuerpo creador, que porte la idea, que sea el cuerpo de un pensamiento. No el cuerpo separado de sus ideas, separado de todo proyecto universal, separado de todo principio.

Un cuerpo que transite de la postración y la vulnerabilidad a ser el vehículo del empoderamiento de una actitud y un propósito de resistencia y emancipación; en el espacio material que emplace acontecimientos, situaciones de alteración de las correlaciones asimétricas entre dominadores y dominados (relaciones de poder).

Es efectivamente una tentativa arraigada a lo político (no directamente filosófica-teórica); ligar el cuerpo de la humanidad al proyecto y la idea como condición indispensable para el reconocimiento igualitario y libre. Ese proyecto y su discurso, referido, en su radicalidad, a los derechos humanos, reclama un concepto de víctima donde el cuerpo -aún si sufriente- no pueda ser separado de la idea; donde ninguna víctima puede ser reducida a su sufrimiento.

\section{9.- Conclusiones provisorias}

Los argumentos de este texto, aún tentativos y en proceso de construcción, han develado la centralidad de la noción de víctima en el siglo XXI, así como sus implicaciones en la ética contemporánea y consecuentemente al discurso de los derechos humanos. Esta visibilidad de la víctima no refiere principalmente a una visibilidad sociológica o histórica, consiste en haber logrado que el sufrimiento de las víctimas deje de ser insignificante, subvierte el confinamiento invisibilizante de las víctimas evitando su aislamiento simbólico, la privatización incomunicable de su dolor y la invisibilidad política. Así, logra actualizarse el nudo fundamental del pensamiento clásico de los derechos humanos: víctima-violencia-dignidad.

Asimismo, se reconoce, desde una doble plano, la posibilidad de comprender a la víctima como: a) la víctima es punto de partida metodológico, plausible para una investigación crítica del núcleo básico ético de una teoría de los derechos humanos y, b) la víctima como mediación necesaria con la dignidad dañada o vulnerada a través de las múltiples formas de violencia(s) y de vulneración de la dignidad de las personas.

Los derechos humanos son aptos para situar discursivamente a la víctima, en términos de saber práctico y expresividad simbólica, como espacio significante de la humanidad entera golpeada; en ser referencia valorativa y práctica para una política que vuelva a ligar ese cuerpo sufriente al proyecto y a la idea, a partir del a priori de la igualdad. ${ }^{65}$ Una reformulación de lo que la vieja filosofía

${ }^{65}$ La igualdad es el meta-referente de la dignidad, entendida como un concepto vacío de significados (altamente polémicos y de consenso intransitable en cuanto a sus contenidos y/o fundamentaciones) y que opere al modo de un postulado de la razón práctica contemporánea, referencia valorativa ideal (abstracta) para la regulación de la convivencia social. Jacques 
llamaba justicia. Se trata aquí y apenas, de un esbozo inicial del horizonte de un vínculo orgánico posible entre una noción crítica de víctima y el discurso y la práctica de los derechos humanos.

La perspectiva de las víctimas, su centralidad en la política de defensa y promoción de los derechos humanos ofrece un fundamento para una ética de la resistencia desde condiciones de vida dañadas, probablemente sin remedio. La reconciliación y su nudo dramático, el perdón convertido en opción política colectiva de las víctimas, expectativa de emancipación. 